\title{
UM OLHAR ANTROPOLÓGICO TRANSFORMADOR NO PROCESSO RELIGIOSO TENDO COMO BASE A MATRIZ CRISTÃ EVANGÉLICA
}

\section{ARTIGO ORIGINAL}

ABRUNHOSA, Juremir Costa ${ }^{1}$

ABRUNHOSA, Juremir Costa. Um olhar antropológico transformador no processo religioso tendo como base a matriz cristã evangélica. Revista Científica Multidisciplinar Núcleo do Conhecimento. Ano 05, Ed. 08, Vol. 11, pp. 101-108. Agosto de 2020.

ISSN:

2448-0959,

Link

de

acesso: https://www.nucleodoconhecimento.com.br/ciencia-da-religiao/processo-

religioso

\section{RESUMO}

O objetivo deste artigo é iniciar um fórum de debate sobre o processo religioso de matriz cristã evangélica, a partir de um olhar antropológico, em seus próprios conceitos, em relação ao discurso e prática, em confronto com pautas alicerçadas num fundamentalismo promotor de pensamentos mágicos em detrimento da diversidade, pluralidade e respeito ao outro, e com gênese na representatividade que se clareira na intercessão histórica e filosófica do preconceito das relações sociais, como elemento reforçador e redutor da convivência e dialética. $O$ que percebemos praticamente aqui é o grande desafio das comunidades cristãs dentro de uma evocação pedagógica em direção a justiça social e na luta da busca de fontes de virtudes de grupos religiosos que não se apresentem burocráticos $e$ institucionalizados. Acreditamos, portanto, que, de maneira bem lúcida, o religioso

${ }^{1}$ Especialização em Antropologia - Universidade Cândido Mendes; Enfermagem e Obstetrícia - Universidade Gama Filho; Teologia - Universidade Metodista de São Paulo " cursando sexto período". 
inclua a Cultura e o Homem na construção do discurso convertido e justificado por Jesus Cristo.

Palavras-chaves: Matriz Cristã, processo religioso, ciência da religião, cristianismo.

\section{INTRODUÇÃO - AS MUITAS LENTES DA ANTROPOLOGIA}

Inicialmente o debate desse artigo será em desenhar um estudo da Antropologia,

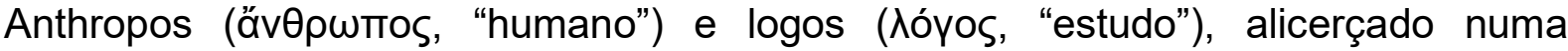
perspectiva, em que o objeto de estudo tem abrangência nas ciências sociais, quanto a reflexão do homem em confronto da prática e o discurso no processo religioso de matriz cristã, bem como suas características comportamentais e formadoras destes grupos sociais consumidores de demandas plurais, em organizações reducionistas, em desenvolvimento nas esferas multifatoriais e interdisciplinares das dimensões humanas.

O entendimento antropológico estabeleceu-se como fundamento importante na reflexão do homem sobre si mesmo e a sociedade em que vive, alavancando formas de pensar com manifestações primeiras, que buscaram alcançar legitimidade na segunda metade do século XIX em apropriação de objetos de estudos empíricos que extrapolaram as civilizações Europeias ou Norte-americanas, com demarcações de áreas longínquas dentro de um nível de complexidade, chamadas de "sociedades primitivas", algo como um "modelo reduzido", em princípios gerais e mesmo universais poderiam ser isolados. Entretanto, essas argumentações são generalizações simplificadoras que tendem a uma ideia conceitual centrada na hiper valorização da escolha dos objetos de estudos em detrimento dos marcos teóricos e metodológicos.

Hoje em dia, os por quês se ratificam devido a uma construção radical que são percebidas em estudos por meio das relações de contrastes, distinções, diversidades, pluralidades e diferenças do homem em sociedade, dentro de uma visão integrada, multifatorial e interdisciplinar em que os recortes temáticos não são norteados por concepções de bases territoriais, temporais ou etnocêntricas das diversas dimensões assumidas pelo homem de conceituação ontológica. 
Os ramos da Antropologia são (1) o pré-histórico instrumentalizado em procedimentos sistemáticos em busca de qualquer elemento importante restaurador da (construção) histórico critico; (2) fenomenológico social e religioso; (3) arqueológico dentro de um processo investigativo na busca de entendimentos sobre as transformações e impactos em sociedades; (4) linguístico que são apropriadas e recriadas expressões de comunicação; (5) psicológica como eixo da dimensão inseparável do todo; (6) física com seu objeto de estudo a partir de variáveis biológicas e comportamentais dos humanos e de seus antepassados e (7) cultural trabalha em conhecer a lógica ontológica do objeto nas relações de troca demostradas nos fenômenos sociais.

\section{A RELIGIÃO NUM OLHAR ANTROPOLÓGICO}

O sentimento religioso é o pressuposto do processo consolidado e institucionalizado denominado (religião), em que “(...) as experiências individuais do religioso fazem pensar em emocionalistas, como Rudolf Otto, que na parte inicial da sua obra, O Sagrado (1992)", citado por (PEREIRA, 2016, p.272 ) como uma experiência emocional profunda e denominando em numinoso, que "apresenta-se como mysterium tremendum, que tanto pode fascinar como ser repulsivo." (Op. cit.)

Mas o mistério no sentimento religioso é a experiência do totalmente outro, "aquilo que nos é estranho e nos desconcerta, o que está absolutamente fora do domínio das coisas habituais, compreendidas, bem conhecidas por conseguinte, «familiares»; é o que se opõe a esta ordem de coisas e, por isso, nos enche de espanto que paralisa" (OTTO, 1992, p. 39). Nestes momentos e nestes estados de "recolhimento solene e de arrebatamento" (OTTO, 1992, p. 18), está presente aquilo que Otto designa como "sentimento do estado de criatura", ou seja, "o sentimento da criatura que se abisma no seu próprio nada e desaparece perante o que está acima de toda a criatura" (OTTO, 1992, p.19). (Op. cit.)

Nesse mistério transcendental a religião se constitui como mediação entre o homem e o sobrenatural para as respostas que assolam e infringem as sociedades, nos confrontando com o pensamento positivista de que a evolução da sociedade é diretamente proporcional ao nível de organização. Pereira (2016) afirma que a "proposta pelo autor cristão Lactâncio, na sua obra Instituições Divinas, remete para 
o termo religare, que significaria "religiar", expressando "a união do ser humano com outros seres humanos e do humano com o divino" (apud SARRÓ, 2007, p.104).

Religião pode ser definida como um processo paradoxal, "(...) discurso religioso caracteriza-se com um discurso assimétrico, uma vez que as relações entre locutor e leitor se estabelecem em planos distintos: um da ordem espiritual (a voz de Deus) e outro de ordem temporal (os leitores humanos)", por (WILSON, 2003, p.155), complexo, ambíguo, confrontador, que pode apresentar-se de forma violenta ou sem sentido, sendo mediadas pelo encantamento dos mistérios que existem nas relações humanas, medo e excitação diante das construções ritualísticas, em (DOS ANJOS, 2018) onde " (...) Por meio das fórmulas religiosas usadas performativamente, isto é, usadas como ação sobre o outro e por meio da intertextualidade de que lança mão o autor. " (WILSON, 2003, p.156).

\section{CULTURA, PRÁTICA E DISCURSO RELIGIOSO}

A cultura é a apropriação do conhecimento, não pré-determinado, para a vida em comunidade, que deve acarretar assombros dialéticos em suas expressões e manifestações pautadas sempre nas diversidades, e Talal Asad clareia essa perspectiva de compreensão citando (GEERTZ, 1989, p. 83), em seu artigo , cujo tema é "A construção da religião como uma categoria antropológica", nos trilhando a interpretação de que "(...) todas as realizações culturais são realizações religiosas e a linha entre as que o são e as realizações artísticas, ou até mesmo políticas, não é muito fácil de demarcar, na prática" (ASAD, 2010, p. 276)

Nesse sentido, as trocas culturais não podem ser valorizadas com imposição do modelo pronto e acabado, no desenho sistemático, metodológico e contínuo da inferioridade do outro em perspectiva gestacional de uma ética que enalteça as particularidades em detrimento do todo, com consequências que impliquem em vícios nas criações de variáveis sociais geradoras de liberdade. "Portanto, a produção cultural é um reflexo das manifestações sociais que as diferentes culturas constroem", citado por (BARROSO, 2017, p.01-04). 
A valorização da busca do outro, essencialmente voltados para as distinções presentes nas construções sociais plurais, que se expressam por diferentes maneiras de comportamento e organização em sociedade surgindo a necessidade imperiosa do debate. "Isso requer uma revisão da sua existência ecumênica, não somente no sentido confessional, nem somente cristão, mas como parte das religiões de toda humanidade como voz profética, com coração aberto, mente aberta e porta aberta." (RENDERS, 2010, p. 234)."Não se podem separar Deus e o mundo. Quando falamos de Deus, imediatamente temos de falar do mundo como palco de sua atuação.", segundo (PICH; ZWETSCH, 1995, 215)

"No entanto, apesar do intenso processo de secularização instaurado pela modernidade, grupos religiosos fundamentalistas crescem rapidamente, inclusive no Brasil." (DE SOUZA, 2009, p.22) e o fundamentalismo, em contrapartida, coloca-se antes de todo saber, como norma absoluta, juiz, sensor e controlador dos indivíduos que entram, voluntária ou involuntariamente, no seu raio de ação. (BAPTISTA, 2003, p. 165-166), em que temos “(...), resultados imediatos dessa postura fundamentalista de reação em face das transformações sociais impostas pela modernidade são: (1) misoginia; (2) manifestação de ativismo político-religioso de caráter conservador." (DE SOUZA, 2009, p.44)

Conforme a Palestra Ressignificando a Religião ministrada por (DOS ANJOS, 2018) afirma que toda essa ideologia religiosa indutora da modernidade, talvez a dimensão mais forte, mais densa da ideologia da modernidade, como semente que foi tanto do iluminismo como do empirismo, toda ela se recompõe, se recolhe, se encolhe, se reformula e se transforma em um discurso legalista, sensor, opressor, não intelectual. Consequentemente (ASAD, 2010, p. 276) afirma que "(...) o status autoritativo das representações/discursos é dependente da produção adequada de outras representações/ discursos; ambos estão intrinsecamente, e não apenas temporalmente conectados."

E a gênese de toda essa representatividade se clareia na intercessão do preconceito, racismo e da violência institucionalizada, que agem como elementos reforçadores políticos, históricos, filosóficos e ideológicos, na perpetuação desses conflitos como 
forma de controle e manipulação na relação de poder, conforme (DOS ANJOS, 2015 ) fala no Fórum Social Libertas "Cobeligerância - convergência na luta, divergências na fé".

Para se entender como a dominação se reproduz é preciso investigar os elementos inerentes nos discursos dos dominantes e dos dominados; ou seja, de indivíduos pertencentes aos "grupos dominados" que podem variar de discurso, de táticas e de rejeições, pois estão sempre num processo de reelaboração do próprio discurso, além de negociarem na relação como o outro suas identidades de tal forma que as representações (naturalizadas) de subordinação passam a ser, cada vez, mais complexas. (BANDINI, 2005, p.83)

A minimização da convivência e da dialética nos espaços inter-religioso, diante das diversidades nos processos podem se apresentar como um paradoxo significativo que permeiam as sociedades num contexto da dualidade, entre céus e infernos, se manifestando como princípio norteador criminalizador da fé divergente aos padrões aceitos, em que os direitos humanos explica (PADILLA, 2015) em Congresso Missão Integral.

Portanto, a luta caminha em estabelecermos uma consciência do respeito e da tolerância, veementemente não opinativa como juízo das formas institucionais e burocráticas de religião, e estas por sua vez, se mantêm e alarga como variáveis restringidoras positivas nas perceptivas dos debates nas manifestações sociais religiosas, afirma (KIVITZ, 2019) no sexto encontro de Espiritualidade Cívica

E essa religiosidade popular explicada por (DOS ANJOS, 2018) caminha nos espaços de situação de vulnerabilidade, nas periferias, locais de sofrimentos existem solidariedades, e uma espécie de fé potencial entre os viventes que se manifesta de forma inspiradora e se conduz como alicerce na resistência do invento da vida. Essa fé potencial em defesa da vida, sem hierarquia social, à favor de uma construção conjunta de conceitos não iguais, em que as manifestações das muitas dimensões se permeiem nas diferenças que traçarmos nos caminhos em oposição a singularidade, para criarmos definições mais justas, humanas, solidárias e espirituais. 
Portanto, as vidas mazeladas e doentes que se encontram vulneráveis a modelos sistemáticos perpetuados na síntese da criminalização da fé do outro, se constituindo como luta de todos e para todos. Para tanto, Fabiano Veliq apresenta como tema central uma produção científica que expressa a relação entre linguagem e religião no pensamento de Rubem Alves. Percebe-se que a linguagem religiosa, no pensamento alvesiano, abre-se para a esperança e para a tolerância. (VELIQ, 2014)

\section{CONCLUSÃO}

O grande desafio do evangelicalismo nacional seria evocar o espírito de Deus presente nas Escrituras Sagradas Cristã , como base de alimento religioso em direção a um pluralismo de expressão e manifestação, em busca do tesouro, como essência a evocação pedagógica de Deus, na direção do assombro e da justiça social, internalizados pela justificação da crença no sobrenatural segundo (PADILLA, 2015).

O desenho desta matriz, em tempos de reacionarismos, deverá se mostrar como elemento engajador, ao "povo de Deus" que se converteu ao espírito do Evangelho, como agente sistemático e esclarecedor do esforço nas práticas de perdão, misericórdia, generosidade com o outro, compaixão, justiça, amor ao próximo e no que the concerne essas fontes de virtudes apresenta-las aos grupos religiosos como não burocráticas e desinstitucionalizadas estando sempre presentes na própria vivência do discurso convertido ao Jesus Cristo., assim entende (DOS ANJOS, 2015).

Concluo, para que sejamos crianças, que não se convertem a religião de forma sistemática, e nem tão pouco valoriza a experiência transcedental a partir do Sagrado Institucionalizado e Burocrático, ou seja pintemos o mundo da realidade prosseguindo no lúdico, poético e imaginativo como interpretação e apropriação dos fenômenos sociais. (DOS ANJOS, 2018) em que Cruz seja o pincel do autor, na letra de Marcus Lucas. 


\section{REFERÊNCIAS}

ASAD, Talal; A construção da religião como uma categoria antropológica, São paulo, ano 2010, n 19. Disponível em: <http://www.revistas.usp.br/cadernosdecampo/a rticle/view/44990 > Acesso em: 29 mar. 2020.

BANDINI , Claudirene A. P. . Corpos, Símbolos e Poder: marcadores de desigualdades sociais no espaço religioso, São Paulo, ano 2005, n 02. Disponível em <http s://www.pucsp.br/rever/rv2_2005/t_bandini.htm> Acesso em: 29 mar. 2020.

BAPTISTA, Saulo. Fundamentalismo e Modernidade, São Paulo, ano 2003, n 08. Disponívelem<http://www.scielo.br/scielo.php?pid=S1415-47142014000600761 \&script=sci_arttext_plus\&tlng=pt>Acesso em: 29 mar. 2020.

BARROSO, Priscila Farfan. Antropologia e cultura / Priscila Farfan Barroso, Wilian Junior Bonete, Ronaldo Queiroz de Morais Queiroz ; [revisão técnica: Guilherme Marin].- Porto Alegre: SAGAH, 2017.

DA SILVA, Eliane Moura .Religião, Diversidade e Valores Culturais: conceitos teóricos e a educação para a Cidadania, São Paulo, ano 2004, n 02. Disponível em <http://www.educadores.diaadia.pr.gov.br/modules/mydownloads_01/visit.php?ci $d=37 \&$ lid=1730> Acesso em: 29 mar. 2020 .

DE SOUZA , Robson da Costa . et al. Discursos e práticas fundam,entalistas na Igreja Presbiteriana do Brasil ( 2002-2008) - Uma análise de pretensa posição de equidistância dos extremos fundamentalistas e liberais. Dissertação (Dissertação em ciências da religião) - UNIMESP. São Bernado do campo , p. 22. 2009.

DOS ANJOS , Felipe .Ressignificando a Religião. Youtube, 30 mai. 2018. Disponível em <lhttps://www.youtube.com/watch?v=3RihD-csHUc>. Acesso em: 25 mar. 2020.

DOS ANJOS, Felipe .Redenção da ética - Fórum Social Libertas. Youtube, 31 jan. 2015. Disponível em <https://www.youtube.com/watch?v=qAcRfwcoaSE\&t=1009s>. Acesso em: 25 mar. 2020. 
KIVITZ, Rene .Ética, Estética e Espiritualidade. Youtube, 20 jul. 2019. Disponível em<https://www.youtube.com/watch?v=xpTa2V6qQFo>. Acesso em: 25 mar. 2020.

PADILLA, Rene .Congresso Missão Integral RP. Youtube, 15 set. 2015. Disponível em $<$ https://www.youtube.com/watchtime_continue $=215 \& v=6 T S r 4 M 8 S d a 8 \&$ feature $=e$ mb_title> Acesso em: 25 mar. 2020.

PEREIRA, Pedro. Uma Viagem Restrpetiva à Antroplogia da Religião, Universidad de Jaén (España), ano 2016, n 16. Disponível em: <https://revistaselectronicas.u jaen.es/index.php/rae/article/download/2441/2514/> Acesso em: 29 mar. 2020.

PICH; Roberto Hofmeister; ZWETSCH, Pich/Roberto Ervino (1995). Elementos de um Novo Paradigma de Missão - Breve Exposição do Pensamento de David J. Bosch. Estudos Tèológicos, 35(2):211-215, 1995

RENDERS, Helmut. "Graça, salvação e teologia da sustentabilidade como tema da teologia wesleyana: discussões, acentos e contribuições". In: Teocomunicação, vol. 40 , n. 2, p. 213-237 (maio/ago. 2010). Disponível em: < http://revistaseletronicas.pucrs. br/ojs/index.php/teo/article /view/6705/5711 >. Acesso em: 05 abr. 2020.

WILSON, Victória. Modos de ler o discurso religioso, UFRJ, Rio de janeiro, ano 2003, n. III. Disponível em: <http://www.e-publicacoes.uerj.br/index.php/soletras/article/ download/4466/3268> Acesso em : 30 mar.2020.

VELIQ , Fabiano. .Dizer e Viver a esperança Aspectos sobre Linguagem e Religião no pensamento de Rubem Alves, Minas Gerais, ano 2014, n 02. Disponível em <http://revista.faculdadeunida.com.br/index.php/reflexus/article/download/239/25 4> Acesso em: 29 mar. 2020.

Enviado: Julho, 2020.

Aprovado: Agosto, 2020. 